Manuscript received November 8, 2014; accepted for publication January 21, 2016; published online March 22, 2016.

${ }^{1}$ Dept. of Mechanical Engineering, Semnan Branch, Islamic Azad Univ., Km. 5 of Semnan-Damghan Rd., Semnan, Iran; and School of Mechanical, Aerospace and Civil Engineering, The Univ. of Manchester, Manchester, United Kingdom (Corresponding author), e-mail: yasharejavadi@yahoo.com; yashar.javadi@manchester.ac.uk

2 Dept. of Mechanical Engineering, Semnan Branch, Islamic Azad Univ., Km. 5 of Semnan-Damghan Rd., Semnan, Iran.
Yashar Javadi ${ }^{1}$ and Seyed Hatef Mosteshary ${ }^{2}$

\section{Evaluation of Sub-Surface Residual Stress by Ultrasonic Method and Finite-Element Analysis of Welding Process in a Monel Pressure Vessel}

\section{Reference}

Javadi, Y. and Hatef Mosteshary, S., "Evaluation of Sub-Surface Residual Stress by Ultrasonic Method and Finite-Element Analysis of Welding Process in a Monel Pressure Vessel," Journal of Testing and Evaluation, Vol. 45, No. 2, 2017, pp. 441-451, http://dx.doi.org/10.1520/JTE20140440. ISSN 0090-3973

\section{ABSTRACT}

Welding of nickel-based alloys is increasingly used in the industry to manufacture various important structures in the marine industries, chemical processing, etc. This study investigates evaluation of sub-surface residual stresses, which are produced by the welding process in a pressure vessel made from Monel 400 alloy. The residual stresses are experimentally measured by ultrasonic method in which longitudinal critically refracted ( $L C R$ ) waves are propagated inside the specimen to evaluate the effect of stress on the wave velocity. Any difference in the wave velocity could be transformed to the material stress by using acoustoelasticity relations. A nondestructive hydro-test process is used to measure the acoustoelastic constant, which is an important material property needed to be embedded in the acoustoelasticity relations. By using a different frequency range than the ultrasonic transducers, the LCR wave penetrates in different depths of the specimen to measure the sub-surface stresses. The welding processes are also numerically analyzed by a 3D thermo-mechanical finite-element (FE) model, which is validated by hole-drilling stressmeasurement method. The residual stresses calculated by FE simulation are then compared with those obtained from the ultrasonic stress measurement and an acceptable agreement is achieved. It is demonstrated that the sub-surface residual stresses of the Monel pressure vessel could be accurately evaluated by combination of the FE simulation and stress measurement implemented by the LCR waves.

\section{Keywords}

Monel 400 Alloy, pressure vessel, finite-element welding simulation, acoustoelasticity, ultrasonic, LCR wave 


\section{Introduction}

\section{WELDING OF MONEL ALLOY}

Monel is a trademark for a series of nickel alloys, composed of nickel (up to $63 \%$ ) and copper, with some iron and other trace elements. With an exceptional resistance to many corrosive environments, Monel 400 alloy is a solid-solution alloy having considerable strength and toughness over a wide temperature range [1]. Monel 400 is extensively used in many industries, particularly marine and chemical processing, for production of valves, pumps, marine fixtures, fresh water tanks, crude petroleum stills, process vessels, piping, boiler feed water heaters, deaerating heaters, etc. [1]. In the majority of Monel applications, the welding process is considered as an important manufacturing process. Generally, conventional welding processes could be used to produce high-quality joints in nickel alloys. The welding procedure specifications (WPS) for nickel alloys could be analogous to those used for the austenitic stainless steels. However, some of the characteristics of nickel alloys necessitate employing different practical techniques compared with those used for the steels [1]. In this study, Monel specimens are joined by employing the tungsten inert gas (TIG) welding process, which is widely used for joining of the nickel alloys.

\section{WELDING RESIDUAL STRESS}

Residual stress is defined as the stress that remains inside the material after the manufacturing process, in the absence of external loads or thermal gradients. The residual stresses influence the materials properties including the fatigue life, deformation, dimensional stability, corrosion resistance, and brittle fracture. As an essential manufacturing process, welding could produces high amount of the residual stresses in the structures. Weld solidification and cooling generates differential shrinkages, which is responsible for the welding residual stresses. By minimization of the welding residual stresses, it is expected to decrease risk of catastrophic failures in the structures. However, it is first needed to evaluate the welding residual stresses. The residual stresses could be determined by numerical and experimental methods, which are simultaneously considered in this study.

\section{COMPUTATIONAL WELDING MECHANICS (CWMS)}

With the development of computer and numerical methods, finite-element (FE) welding simulation has become a popular and reliable technique for the prediction of the welding residual stress and deformation. It has been more than 40 years since Ueda and Yamakawa [2] first described a thermal-elastic-plastic finite-element method (FEM) to predict the welding residual stress and deformation. However, the majority of studies conducted before the year 2000 simulated the welding process by using two-dimensional (2D) FE models, which have serious limitations in prediction of welding residual stress and particularly welding deformations. Recent development in numerical capabilities of the computers as well as in the FE packages has motivated the researchers to analyze the residual stresses and deformations by employing three-dimensional (3D) FE models, which are also used in this study. Under the efforts of many researchers, much progress has been made in the field of CWMs, which has been an important branch in the area of welding science and technology $[3,4]$. The CWM is used in this study to calculate the welding residual stresses in a Monel pressure vessel.

\section{STRESS MEASUREMENT BY THE LONGITUDINAL CRITICALLY REFRACTED (LCR) ULTRASONIC WAVES}

The welding residual stresses could be experimentally measured by various destructive and nondestructive methods. Ultrasonic stress measurement is a nondestructive method based on the acoustoelasticity law, which states that flight time of the ultrasonic wave is influenced by the material stress. Thompson et al. [5] and Schneider [6] described the stress measurement by the ultrasonic method. The shear type ultrasonic waves were previously used for ultrasonic stress measurement but, in modern applications of the technique, LCR waves are substituted. The LCR wave is a longitudinal ultrasonic wave propagated parallel to the surface. Egle and Bray [7] showed that sensitivity of the LCR wave to the stress is highest among other types of the ultrasonic waves. Various applications of the LCR technique were given in a number of studies, remarkably Santos and Bray $[8,9]$, Bray and Chance [10], and Javadi et al. [11-15]. The LCR waves are employed in this study to measure the welding residual stresses of the Monel specimen.

\section{SUB-SURFACE RESIDUAL STRESS}

Sub-surface residual stresses are defined as the stresses within depth of the materials. In the circumferential welding needed to manufacture the pressure vessels, the residual stresses in depth of material could be considerably different from the surface stresses. However, the majority of nondestructive stress measurement techniques, like $\mathrm{x}$-ray diffraction and Barkhausen noise, are capable of surface stress measurement in a depth of a few micro-millimeters [16]. The ultrasonic method has shown the capability of sub-surface stress measurement in the stainless steel plates and pipes $[17,18]$. By changing frequency of the ultrasonic transducer by which the ultrasonic wave is produced, the LCR wave is able to penetrate different depths of the material to measure the sub-surface residual stresses. However, potential of the sub-surface stress measurement in the nickelbased alloys needs more investigation, which is considered in this study.

\section{MAIN GOAL AND OBJECTIVES OF THIS STUDY}

In the previous literature, the CWM has been scantly considered in the nickel-based alloys, particularly in Monel. 
Furthermore, sub-surface stress measurement of Monel pressure vessel has not been considered in any other publication. Although the LCR method has been employed by Javadi [19] in Monel, the main focus of that study was on the straight welding in plates that suggest completely different trends of residual stress in comparison with the circumferential welding considered here. The main goal of this study is sub-surface stress evaluation of the Monel pressure vessel by simultaneous implementation of the CWM and LCR methods. The welding process is first simulated to predict the welding residual stresses. The residual stresses are also measured by the hole-drilling incremental method to validate the FE results. The LCR method is then employed to measure the sub-surface residual stresses. By comparing results of the CWM and LCR methods, a comprehensive knowledge of the sub-surface stress distribution will be achieved in the Monel pressure vessel.

\section{Theoretical Background}

\section{STRESS MEASUREMENT BY THE LCR ULTRASONIC WAVES}

Fig. 1 shows an experimental configuration commonly used in stress measurement by the LCR ultrasonic waves. The LCR wave is first produced by a transmitter transducer, then propagated through a region of the material and is finally detected by one or two receiver transducers. In this wave path, the velocity of the LCR wave is influenced by the material stress. The residual stress in a sub-surface layer is determined while the depth of the layer is related to the ultrasonic wavelength, often exceeding a few millimeters. First critical angle in which the LCR wave is produced and received by the transducers is calculated equal to $31^{\circ}$ in case of passing from the PMMA wedge and propagating in the Monel alloy (Fig. 1).

The relation between measured travel-time change of the LCR wave and the corresponding uniaxial stress is derived by Egle and Bray [7] to be:

FIG. 1 LCR wave propagated in the Monel pressure vessel.

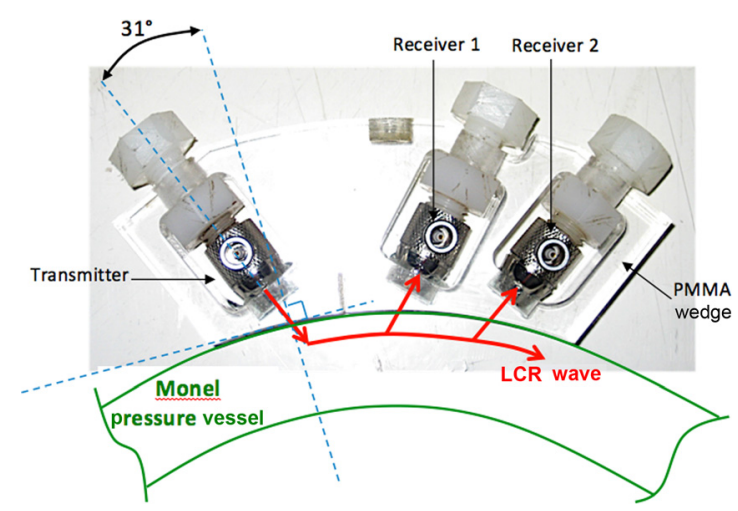

$$
\Delta \sigma=\frac{E}{L t_{0}}\left(t-t_{0}-\Delta t_{T}\right)
$$

where:

$\Delta \sigma=$ stress variation [(transient stress) - (initial stress)],

$E=$ the elastic modulus,

$L=$ the acoustoelastic constant related to the longitudinal wave propagated in the direction of the applied stress,

$t=$ the experimental travel time needing to be measured in the welded specimen,

$t_{0}=$ travel time for a homogeneous, isotropic, stress-free sample at room temperature, and

$\Delta t_{T}=$ the effect of temperature gradient between the room and the measured temperature.

With knowledge of the weld-induced change in travel time, as well as the acoustoelastic constant, the stress variations could be achieved.

\section{FINITE-ELEMENT WELDING SIMULATION}

Numerical simulation of the welding residual stresses needs to accurately consider the relations between heat transfer, metallurgical transformations, and mechanical fields. The phenomenon is involved in the heat input, such as arc material interactions as well as fluid dynamics in the weld pool. Because the finite-element method is fundamentally a continuum-level calculation, hence, simulation of the microstructural evolution is considered through simulation of the material properties changes at expected transformation times and temperature. From the thermo-mechanical point of view, the heat input can be simulated as a volumetric or surface energy distribution. The fluid flow effect, which leads to homogenizing the temperature in the molten area, can be taken into account by increasing the thermal conductivity over the melting temperature. Heat transfers in solids are described by the heat equation as:

$$
\begin{gathered}
\rho \frac{d H}{d t}-\operatorname{div}(k \nabla T)-Q=0 \\
k \nabla T \cdot n=q(T, t) \quad \text { on } \partial \Omega_{q} \\
T=T_{p}(t) \quad \text { on } \partial \Omega_{t}
\end{gathered}
$$

where:

$\rho=$ density,

$k=$ thermal conductivity,

$H=$ enthalpy,

$Q=$ internal heat source,

$T=$ temperature,

$n=$ the outward normal vector of domain $\partial \Omega$,

$q=$ the heat flux density that could rely on temperature and time to model convective heat exchanges on the surface, and

$T_{p}=$ a prescribed temperature.

The welding heat input is represented by an internal heat source. In this study, the double ellipsoid heat-source pattern 
TABLE 1 Chemical composition of Monel 400 used in this study.

\begin{tabular}{lccccccc}
\hline Element & $\mathrm{Ni}$ & $\mathrm{Cu}$ & $\mathrm{C}$ & $\mathrm{Si}$ & $\mathrm{Mn}$ & $\mathrm{S}$ & $\mathrm{Fe}$ \\
\hline $\begin{array}{l}\text { Chemical } \\
\text { composition (wt. \%) }\end{array}$ & 64.541 & 32.953 & 0.081 & 0.1 & 0.572 & 0.008 & 1.745 \\
\hline
\end{tabular}

presented by Goldak and Akhlaghi [3] is employed to simulate the heat source. The double ellipsoid model, also known as the Goldak model, is a popular model employing two ellipsoid heat-source patterns to simulate the method of heat transferring from the welding torch into nodes of the FE model. The moving heat source is modeled by a user subroutine in the ANSYS commercial software.

The FE problem is formulated as a sequentially coupled thermo-mechanical analysis. A nonlinear thermal analysis is first implemented to find the temperature history of the entire domain. The thermal results are then applied as thermal body loads in a nonlinear mechanical analysis, which would be responsible for estimation of the residual stress and deformations. The mesh geometry and dimension of the FE model is the same for both thermal and mechanical analysis. The generalpurposed FE package, ANSYS, is used for the analysis. A full Newton-Raphson iterative solution technique with direct sparse matrix solver is employed to reach the solution. During the thermal analysis, the temperature and temperature-dependent material properties are quickly changed. Hence, the full Newton-Raphson technique is expected to give more accurate results.

The common "element birth and death" technique is used to model the deposited weld [3]. A complete FE model is generated in the start of the analysis, while all of the elements representing the deposited weld (except those positioned in the tack welds) are deactivated by assigning them a very low stiffness. During the thermal analysis, all of the nodes of deactivated elements (excluding those shared with the base metal) are fixed at the room temperature until the birth of the corresponding elements. Deactivated elements are reactivated consecutively when the welding torch arrives over them.
The mesh size is optimized to reach high accuracy of the FE model along with low computation time. The mesh optimization, according to the method prescribed by Javadi [19], is implemented by modeling of some specimens with different meshing size. The investigated models are run, and results of the residual stress analysis are compared with those obtained from the hole-drilling measurement. Selecting the most effective mesh size leads to the most accurate estimation of the residual stresses as well as the least time-consuming calculations.

\section{Experimental Procedures}

\section{SAMPLE DESCRIPTION}

In this study, the pipes and caps from Monel 400, with chemical composition according to Table 1, are welded to investigate the welding residual stresses. A pressure vessel is constructed from two Monel 400 pipes, as well as two standard caps, whereas the diameter and thickness is equal to $150 \mathrm{~mm}$ (6 in.) and $7 \mathrm{~mm}$ (0.28 in.), respectively. The pipes and caps are stress relieved at $600^{\circ} \mathrm{C}$ for $6 \mathrm{~h}$, before being employed in the manufacturing process of the pressure vessel. The welding processes include a main weld to join the pipes, welding process of the left cap, right cap welding, as well as nozzle welding are implemented according to the WPS mentioned in Table 2. All of the weld reinforcements are removed by a 30,000-rpm hand grinder to facilitate ultrasonic inspection. However, the elevated temperature, during the grinding process is controlled to prevent generation of thermal stresses.

\section{TOF MEASUREMENT DEVICES}

The measurement devices shown in (Fig. 2) include an ultrasonic box, computer, and time-of-flight (TOF) measuring unit. The ultrasonic box is a $100-\mathrm{MHz}$ ultrasonic testing device that has synchronization between the pulser signal and the internal clock, which controls the A/D converter. This allows very precise measurements of the time of flight-better than 1 ns. The TOF measuring unit includes three longitudinal wave transducers assembled on an integrated wedge to measure the time of flight.

TABLE 2 Welding procedure specifications of the pressure vessel.

\begin{tabular}{|c|c|c|c|c|c|}
\hline Sample & $\begin{array}{l}\text { Pass } \\
\text { No. }\end{array}$ & $\begin{array}{c}\text { Welding } \\
\text { Current (A) }\end{array}$ & $\begin{array}{c}\text { Welding } \\
\text { Voltage }(\mathrm{V})\end{array}$ & $\begin{array}{c}\text { Welding } \\
\text { Speed }(\mathrm{mm} / \mathrm{s})\end{array}$ & Groove Angle: $60^{\circ}$ \\
\hline \multirow[t]{3}{*}{ Main center weld (pipe-pipe) } & 1 & 150 & 20 & 1 & Filler metal material: Monel Filler Metal 60 (AWS A5.14_ER NiCu-7) \\
\hline & 2 & 150 & 22 & 1.5 & Filler metal diameter: $2.5 \mathrm{~mm}$ \\
\hline & 3 & 150 & 20 & 1.5 & Welding Process: TIG welding; Gas: Argon (10 1/min) \\
\hline \multirow[t]{2}{*}{ Cap 1 weld (left cap to pipe) } & 1 & 140 & 20 & 1 & Surface cleaning: Hot water with soap \\
\hline & 2 & 140 & 22 & 1.5 & Surface oxide removing: Grinding $5 \mathrm{~cm}$ distance from the weld \\
\hline \multirow[t]{2}{*}{ Cap 2 weld (right cap to pipe) } & 1 & 140 & 20 & 1 & Interpass cleaning: By the stainless steel brushing \\
\hline & 2 & 130 & 20 & 1.5 & \\
\hline Nozzle & 1 & 120 & 18 & 3 & \\
\hline
\end{tabular}


FIG. 2 Ultrasonic TOF measurement devices.
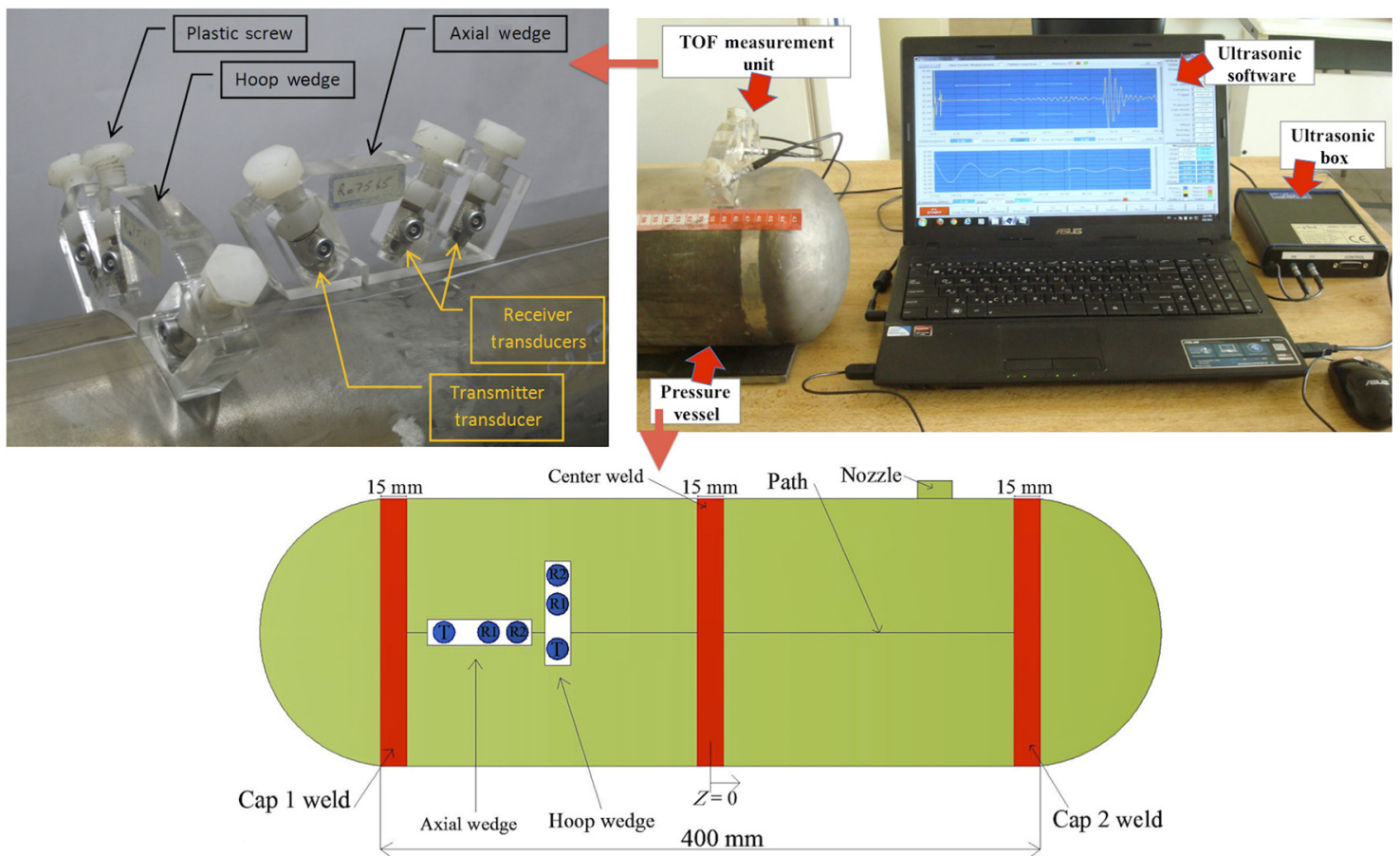

A poly(methyl methacrylate) (PMMA) material, under the trademark Plexiglas, is cut by a laser to construct the wedge. Axial and hoop wedges are employed to measure the TOF in the axial and hoop directions, respectively. A three-probe arrangement including one sender and two receivers is needed to eliminate the effects of environmental temperature on the travel time. Twelve transducers in four different frequencies are used, whereas their nominal frequencies are $1 \mathrm{MHz}, 2 \mathrm{MHz}, 4 \mathrm{MHz}$, and $5 \mathrm{MHz}$. Three longitudinal wave transducers with the same frequency are assembled in each wedge where the diameter of the piezoelectric elements is $6 \mathrm{~mm}$. The scanning paths start from the melted zone (MZ) of the left cap, pass the main center weld, and end to the $\mathrm{MZ}$ of the right cap. The moving step is equal to $1 \mathrm{~mm}$ for the points near and on the MZ, whereas it is increased to $5 \mathrm{~mm}$ further away from the weld. The TOF is measured three times for each point and the average data is recorded. The path should be scanned four times by using the four different frequencies of the transducers. It is worth nothing that the LCR wave is struggling to be propagated inside the Monel because of the texture. The practical difficulties are similar to those already reported in LCR stress measurement of austenitic stainless steels (i.e., beam skewing, splitting, and attenuation) [12,17-20]. Hence, the same methodology of LCR stress measurement in austenitic stainless steel pressure vessels [12] has been employed in this study, which is based on acoustoelastic constant measurement, will be discussed in the following sections throughout the scanning path. This will accurately monitor the material texture to deal with the ultrasonic difficulties posed by the textures in Monel.

\section{DETERMINATION OF THE LCR PENETRATION DEPTH}

When the LCR wave is propagated in a sample with limited wall thickness, the penetration depth is expected to be a function of frequency. However, there is no specific relation available between the LCR depth and frequency. Hence, the LCR depth should be measured experimentally. A variable depth groove is cut in a pipe, with the same material and thickness of the investigated sample, to produce a barrier to physically prevent the LCR wave from reaching the receiver transducer. It is discovered that a 1-mm depth groove could completely prevent a $5-\mathrm{MHz}$-LCR wave to pass, which indicates that the penetration depth of such an LCR wave is $1 \mathrm{~mm}$. Similarly, the penetration depth of $4 \mathrm{MHz}, 2 \mathrm{MHz}$, and $1 \mathrm{MHz}-\mathrm{LCR}$ wave is measured equal to $1.5 \mathrm{~mm}, 3.5 \mathrm{~mm}$ and $7 \mathrm{~mm}$, respectively.

\section{ACOUSTOELASTIC CONSTANT EVALUATION}

To evaluate the acoustoelastic constant $(L)$, the sample needs to be pressurized to purposely produce stress on the surface. The sample is filled with water and the internal pressure is increased step by step through an air compressor. The stress on the outer surface is calculated according to ASME-Section VIII [21]. The sample is retained under a certain pressure, whereas the ultrasonic LCR method is implemented to determine the TOF 
affected by the pneumatic stress. The acoustoelastic constant $(L)$ throughout the sample is then calculated based on Eq 1.

\section{RESIDUAL STRESS MEASUREMENT BY HOLE-DRILLING METHOD}

The residual stresses measured by the ultrasonic method are verified by the hole-drilling technique, which is standardized by ASTM E837 [22] for stress measurement. The hole-drilling method is implemented on the sample in seven points. This semi-destructive technique measures the strains relaxed by incremental drilling of a small hole with diameter of $2 \mathrm{~mm}$. The strains are evaluated using a strain gauge rosette after each depth increment and the residual stresses are then calculated employing equations established by ASTM E837 [22].

\section{Results and Discussion}

The results of finite-element (FE) welding simulation are used for verification of the ultrasonic stress measurement. Hence, first, the FE results need to be validated with those obtained from the hole-drilling measurement (Figs. 3 and 4).

From Figs. $\mathbf{3}$ and $\mathbf{4}$, it is generally observed that the FE model has enough accuracy to be compared with the holedrilling results. It also shown that the hole-drilling technique is implemented in both caps as well as the main center weld, whereas an acceptable agreement with the FE results is achieved in a majority of the points. Furthermore, the agreement is available in both the hoop and axial residual stresses shown in Figs. 3 and $\mathbf{4}$, respectively.
The aforementioned agreement (between the FE and the hole-drilling results) is assumed as verification of the FE model, which is called a validated finite-element model (VFEM) and is now a reliable model for verification of the ultrasonic stress measurement. The VFEM is then employed for calculation of the residual stresses in various depths of the specimen according to those measured as the penetration depths of the LCR waves (as shown in Figs. 5 and $\mathbf{6}$ ).

It has been previously shown that the ultrasonic method is able to measure the average of residual stresses in a depth equivalent to the LCR penetration depth [11-15]. Hence, the results shown in Figs. 5 and $\mathbf{6}$ need to be revised to meet the criteria of average stress measurement. This is shown in Fig. 7 where the average of residual stresses calculated by the VFEM at a depth of $1 \mathrm{~mm}, 1.5 \mathrm{~mm}, 3.5 \mathrm{~mm}$, and $7 \mathrm{~mm}$ are assumed to be equivalent with those obtained from the ultrasonic stress measurement implemented by $5 \mathrm{MHz}, 4 \mathrm{MHz}, 2 \mathrm{MHz}$, and $1 \mathrm{MHz}$ transducers, respectively.

The average of residual stresses is now applicable for verification of the ultrasonic stress measurement results. This is shown in Figs. 8 and $\mathbf{9}$ for each of hoop and axial residual stresses evaluated by various LCR testing frequencies.

From Figs. 8 and 9, it is generally obvious that there is an acceptable agreement between the residual stresses analyzed by the VFEM with those obtained from the ultrasonic method. However, the aforementioned agreement is better achieved when the measurements are implemented by lower testing frequencies ( $1 \mathrm{MHz}$ is better than $2 \mathrm{MHz}$, whereas the worst agreement is observed in measurements implemented by $5 \mathrm{MHz}$ ).
FIG. 3

Comparison of FE and hole-drilling results related to the hoop residual stress.

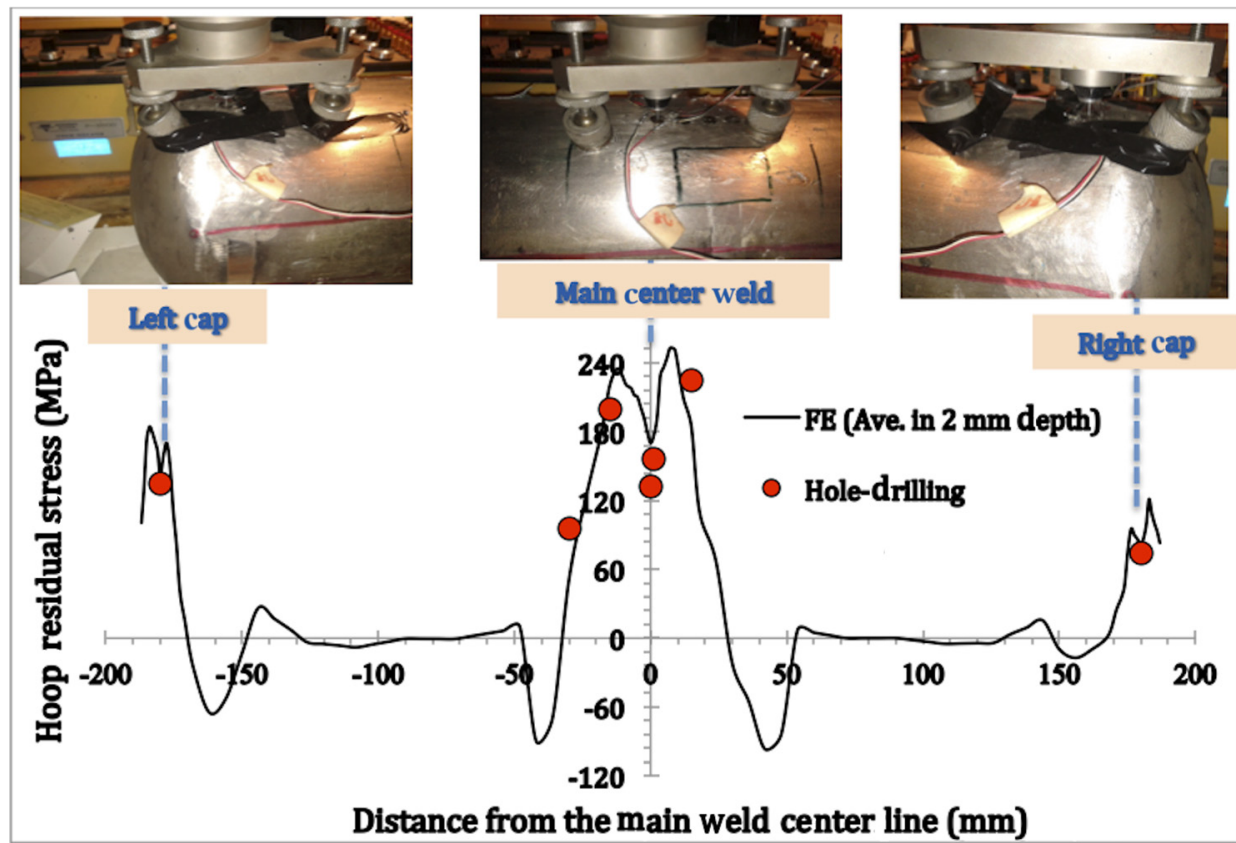


FIG. 4

Comparison of FE and hole-drilling results related to the axial residual stress.

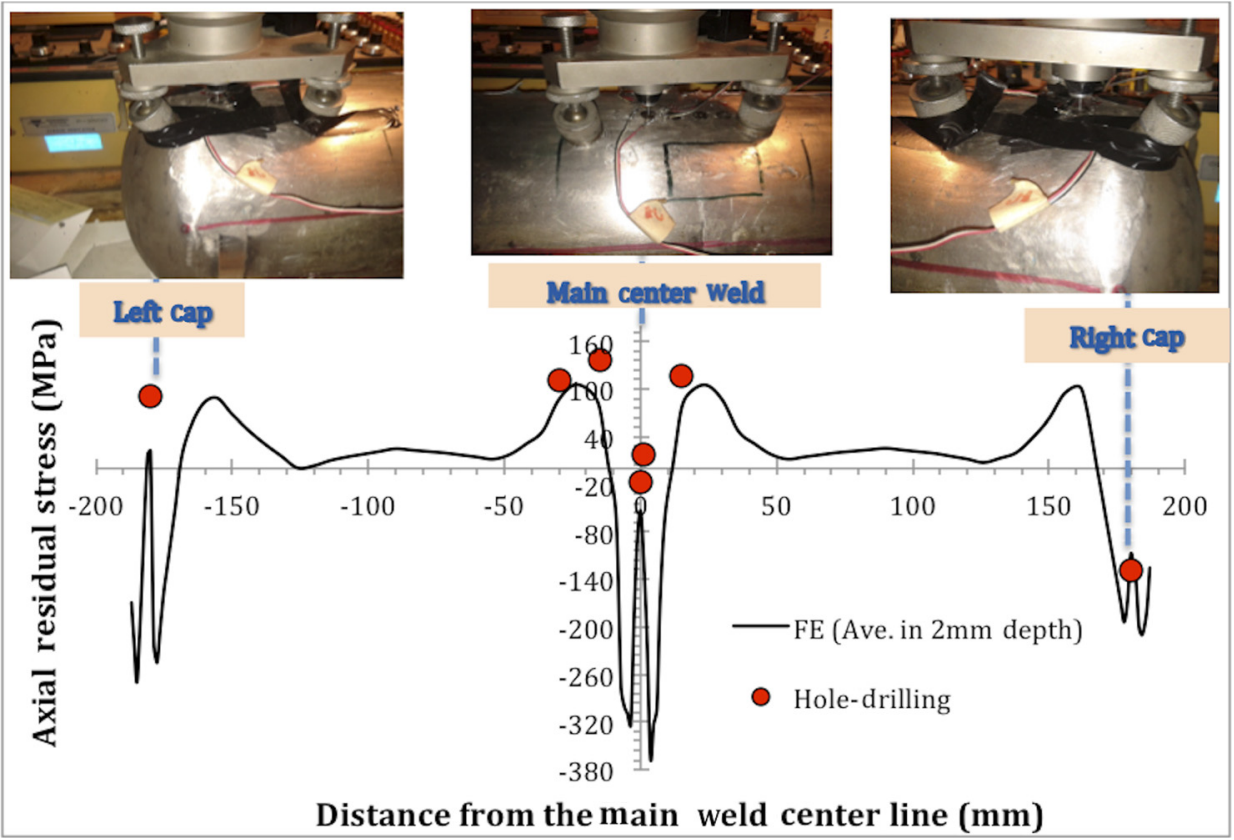

FIG. 5 Hoop residual stresses obtained from the VFEM according to the LCR penetration depths.

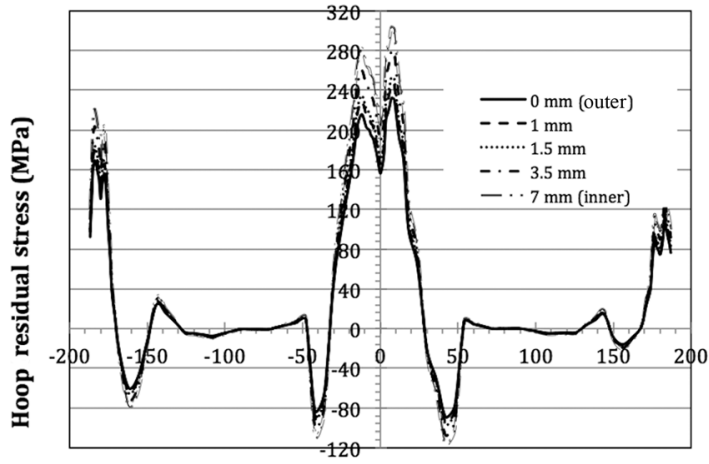

Distance from the main weld center line (mm)

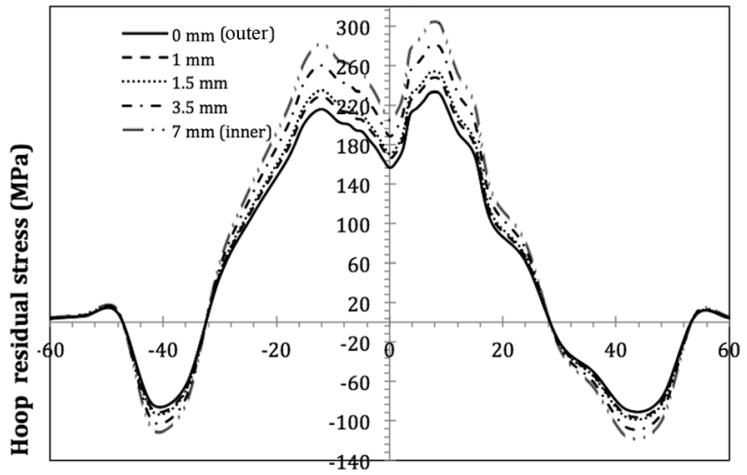

Distance from the main weld center line (mm)

FIG. 6 Axial residual stresses obtained from the VFEM according to the LCR penetration depths.

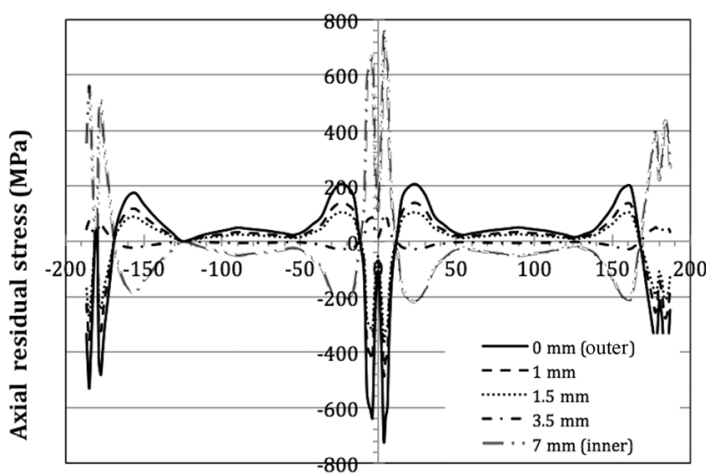

Distance from the main weld center line $(\mathrm{mm})$

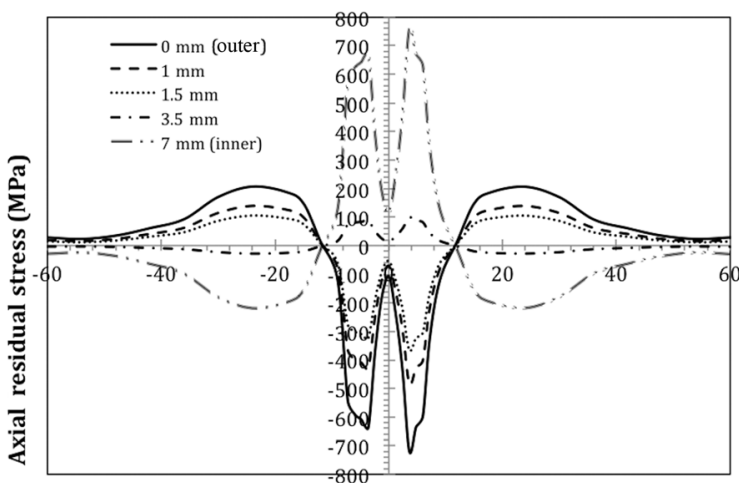

Distance from the main weld center line (mm)

Copyright by ASTM Int'l (all rights reserved); Fri Dec 8 07:06:40 EST 2017

Downloaded/printed by

University Of Strathclyde (University Of Strathclyde) pursuant to License Agreement. No further reproductions authorized. 
FIG. 7 Average of hoop (a) and axial (b) residual stresses calculated by VFEM in depths equivalent with penetration depths of the ultrasonic LCR wave.

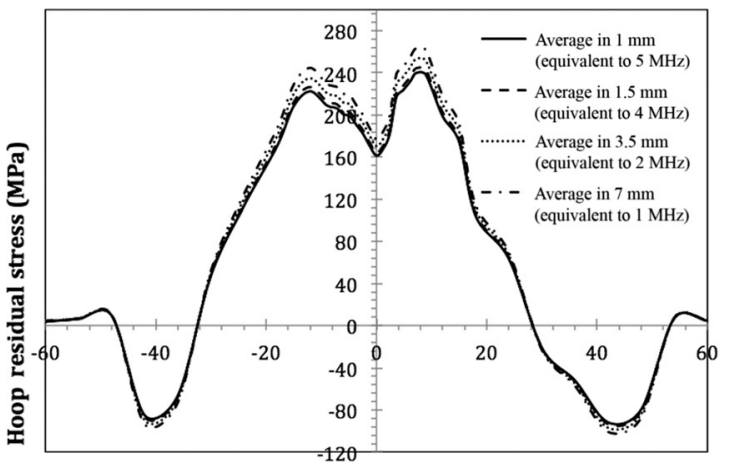

Distance from the main weld centerline (mm)

(a)

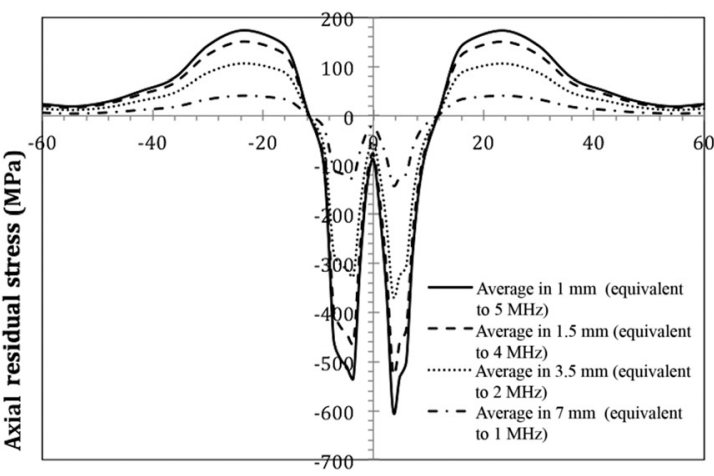

Distance from the main Weld centerline (mm)

(b)
This obviously shows the frequency effect on accuracy achieved by the LCR stress measurement. To this end, the lower frequencies, $1 \mathrm{MHz}$ transducers, suggest higher stress measurement accuracy because of the lower beam scattering in comparison with the high-frequency signals. The deviation between the VFEM and ultrasonic measurements are shown in Table 3.
From Table 3, it is seen that the ultrasonic method is able to measure the residual stresses in the parent material (PM) with higher accuracy compared with the melted zone and heataffected zone (HAZ). Furthermore, better sensitivity of the ultrasonic method is achieved in case of using ultrasonic transducers working with lower frequencies. However, this study is

FIG. 8 Comparison between hoop residual stresses analyzed by the VFEM with those obtained from the ultrasonic method implemented by (a) $5 \mathrm{MHz}$, (b) $4 \mathrm{MHz}$, (c) $2 \mathrm{MHz}$, and (d) $1 \mathrm{MHz}$.

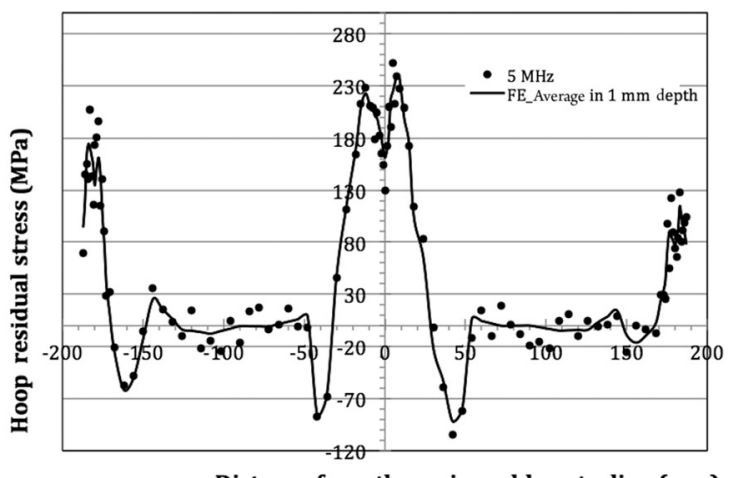

Distance from the main weld centerline (mm)

(a)

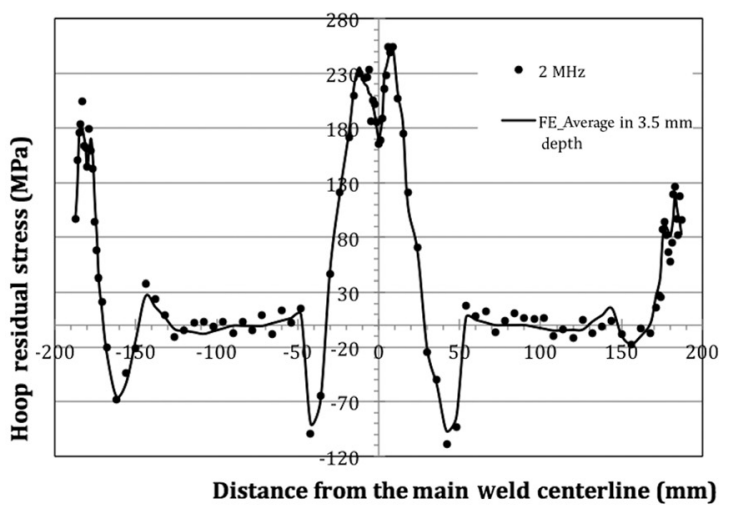

(c)

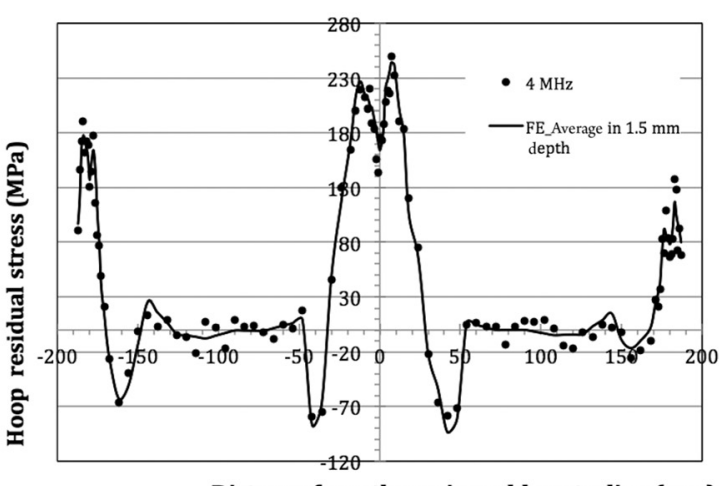

(b)

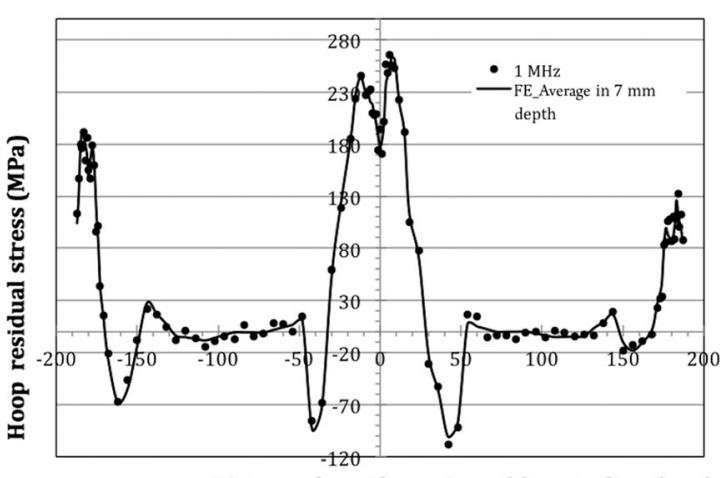

Distance from the main weld centerline (mm)

(d) 
FIG. 9 Comparison between axial residual stresses analyzed by the VFEM with those obtained from the ultrasonic method implemented by (a) $5 \mathrm{MHz}$, (b) $4 \mathrm{MHz}$, (c) $2 \mathrm{MHz}$, and (d) $1 \mathrm{MHz}$.

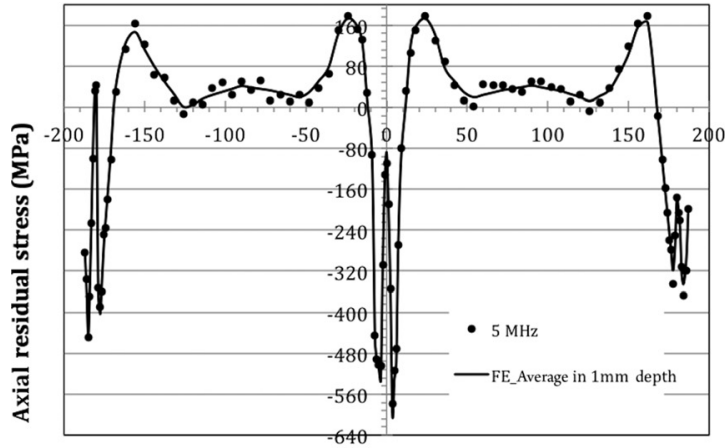

Distance from the main weld centerline (mm)

(a)

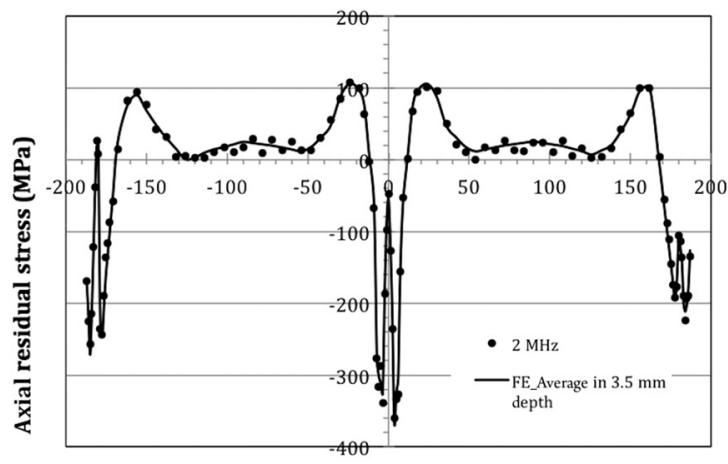

Distance from the main weld centerline $(\mathrm{mm})$

(c)

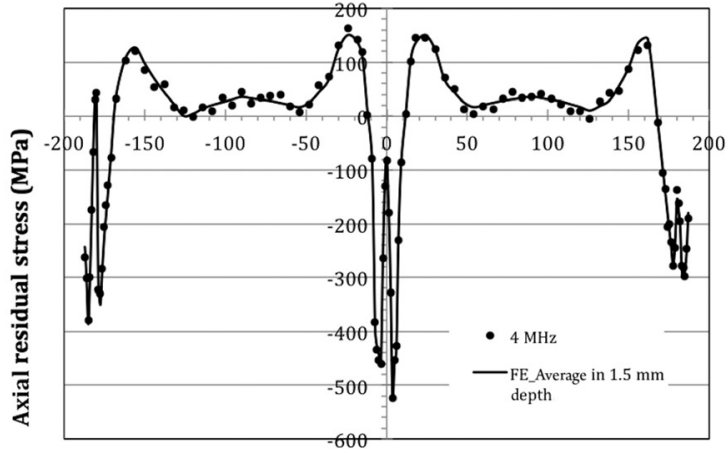

Distance from the main weld centerline (mm)

(b)

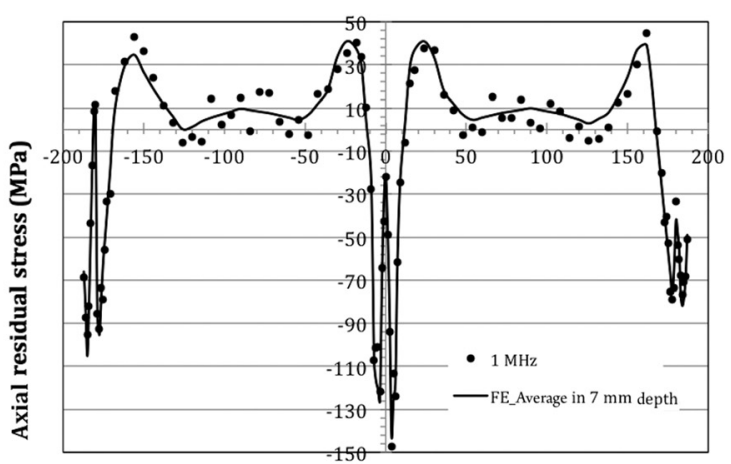

Distance from the main weld centerline (mm)

(d) gaining from low frequency transducers for residual stress measurement in higher depths of the material leading to sub-surface stress measurement in a Monel pressure vessel. Hence, the subsurface stress measurement is practical in nickel-based alloys by using the ultrasonic method.

From Table 3, the maximum of deviation is equal to 38 $\mathrm{MPa}$, which is about $6.7 \%$ of Monel yield strength used in this study. Considering the high yield strength of Monel, it could be concluded that sensitivity of the ultrasonic method is satisfactory to be employed for welding residual stress measurement in this nickel-based alloy. Javadi et al. [20] showed similar deviation (about $40 \mathrm{MPa}$ ) achieved in investigation of stainless steel pressure vessel. It should be noted that the measurement devices used in this study is the same as those employed by Javadi et al. [20]. This is probably the reason similar deviation results (about $40 \mathrm{MPa}$ ) were reached in both studies. By comparing the results of this study with those reported by Javadi et al. [20], it is concluded that accuracy of the ultrasonic stress measurement is independent from the yield strength of the material in which the residual stresses are evaluated. However, it is believed that

TABLE 3 Deviation between FE and ultrasonic results (pipe outer surface inspection).

Frequency of Ultrasonic Transducer Used to Measure the Residual Stress

Maximum of deviation between the VFEM and Hoop residual stress ( $\mathrm{MPa})$ ultrasonic results
Hoop residual stress $(\mathrm{MPa})$

Axial residual stress $(\mathrm{MPa})$
Melted zone

HAZ

$\mathrm{PM}$

Melted zone

HAZ

PM
$4 \mathrm{MHz}$

$5 \mathrm{MHz}$

38

29

19

14

19

28

14

\begin{tabular}{cc}
$2 \mathrm{MHz}$ & $1 \mathrm{MHz}$ \\
\hline 23 & 19 \\
23 & 18 \\
11 & 9 \\
14 & 9 \\
23 & 19 \\
11 & 9
\end{tabular}


TABLE 4 Resolution of the ultrasonic stress measurement achieved in recent publications.

\begin{tabular}{lccccc}
\hline $\begin{array}{l}\text { Resolution of } \\
\text { the Ultrasonic } \\
\text { Stress Measurement }\end{array}$ & Reported in: & Welding Position & $\begin{array}{c}\text { Welding } \\
\text { Zone }\end{array}$ & $\begin{array}{c}\text { Frequency of the Ultrasonic } \\
\text { Transducer by which } \\
\text { the Stress Is Measured }\end{array}$ & $\begin{array}{c}\text { Material in which the } \\
\text { Stress Is Measured }\end{array}$ \\
\hline $\pm 38 \mathrm{MPa}$ & This study & Circumferential welding in a pressure vessel & Melted zone & $5 \mathrm{MHz}$ & Monel 400 \\
$\pm 40 \mathrm{MPa}$ & Javadi et al. [20] & Circumferential welding in a pressure vessel & Melted zone & $5 \mathrm{MHz}$ & Stainless steel (TP 304L) \\
$\pm 40 \mathrm{MPa}$ & Javadi et al. [18] & Circumferential welding in a pipe & Melted zone & $5 \mathrm{MHz}$ & Stainless steel (TP 304L) \\
$\pm 45 \mathrm{MPa}$ & Javadi et al. [17] & Straight welding in a plate & Melted zone & $5 \mathrm{MHz}$ & Stainless steel (TP 304L) \\
$\pm 10 \mathrm{MPa}$ & Sadeghi et al. [23] & Straight welding in a plate & Melted zone & $5 \mathrm{MHz}$ & Aluminum (5086) \\
\hline
\end{tabular}

the welding position (including circumferential welding in pipes and straight welding in plates) as well as the welding zone (including melted zone, HAZ, and PM) could influence the stress measurement accuracy of the ultrasonic method. A brief review of measurement resolution achieved in the ultrasonic stress measurement employed in recent publications is listed in Table 4. All of the data listed in Table 4 are the maximum of deviation between the results of ultrasonic stress measurement compared with those analyzed by a validated FE model. This deviation is considered as the resolution of the ultrasonic stress measurement.

From Table 4, it is concluded that the peak of deviation in the ultrasonic stress measurement method reaches $45 \mathrm{MPa}$. Hence, using the ultrasonic stress measurement is recommended in high-strength materials and particularly in those structures experiencing high levels of the residual stresses, e.g., welded structures, to mask the high amount of the deviation.

It should also be noted that Table 4 shows the maximum of measurement error achieved in the ultrasonic stress measurement, whereas there are various practical techniques to decrease this error into less than $\pm 10 \mathrm{MPa}$ even for stainless steels. Among them, using low-frequency transducers and employing the immersion ultrasonic transducers are two of the most effective techniques for reaching more accurate stress measurement $[13,17,18]$.

The researchers involved in the ultrasonic stress measurement of the stainless steels are always asked about the ultrasonic difficulties of the austenitic stainless steels inspection. The ultrasonic examination of very thick austenitic stainless steel welds is always associated with many difficulties, such as ultrasound attenuation, beam skewing, and beam scattering [24]. However, because of considerable differences between the LCR wave (which is used in the ultrasonic stress measurement) with the ultrasonic waves commonly employed in the ultrasonic testing (UT), the aforementioned difficulties are not observed during the ultrasonic stress measurement. But, these practical difficulties are probably the main reason for the lower resolution of the ultrasonic method implemented in the stainless steels and Monel compared with the aluminum, as noted in Table 4. Furthermore, by comparing this study with the stainless steel works [17-20], it is concluded that the ultrasonic LCR wave is influenced by the inspection difficulties of the austenitic stainless steel, which is the same as the Monel alloy.

\section{Conclusions}

The main goal of this paper is ultrasonic evaluation of welding sub-surface residual stresses in a pressure vessel made of Monel 400 alloy. The ultrasonic measurements are compared with residual stresses obtained from a validated FE model. According to the achieved results, it can be concluded that:

1. The ultrasonic method is able to measure sub-surface residual stresses in Monel alloy with an acceptable accuracy.

2. The welding position and welding zone influence the resolution of the ultrasonic stress measurement whereas the tensile strength could not produce such an effect. For instance, resolution of the ultrasonic stress measurement implemented in Monel alloy is comparable to the stainless steels whereas the yield strengths are considerably different.

3. The inspection difficulties commonly observed during the UT are supposed to be a reason for reaching lower resolutions of ultrasonic stress measurement implemented in the stainless steels compared with aluminum. Similar phenomenon is also observed in Monel stress measurement.

The sub-surface stress measurement with a measurement error of $38 \mathrm{MPa}$ (which is about $6.7 \%$ of Monel yield strength) is a suitable reason to recommend using the ultrasonic stress measurement in high-strength nickel-based alloys with an acceptable reliability.

\section{References}

[1] Special Metal Corporation (SMC), "Special Metals Joining," Publication No. SMC-055, 2003, http://www. specialmetals.com

[2] Ueda, Y. and Yamakawa, T., "Thermal Stress Analysis of Metals With Temperature Dependent Mechanical Properties," Proceedings of the International Conference on Mechanical Behavior of Materials, August 15-20, 1972, S. Taira, Ed., Kyoto, Japan, 1972, No. 3, pp. 10-20. 
[3] Goldak, J. and Akhlaghi, M., Computational Welding Mechanics, Springer, New York, 2005.

[4] Lindgren, L. E., Computational Welding Mechanics: Thermomechanical and Microstructural Simulations, Woodhead, Cambridge, U.K., 2007.

[5] Thompson, R. B., Lu, W. Y., and Clark, A. V., Handbook of Measurement of Residual Stress, J. Lu., M. James, and G. Roy., Eds., Society for Experimental Stress Analysis, Bethel, CT, 1996, pp. 149-178.

[6] Schneider, E., Structural and Residual Stress Analysis by Nondestructive Methods, V. Hauk, Ed., Elsevier, Amsterdam, 1997, pp. 522-563.

[7] Egle, D. M. and Bray, D. E., "Measurement of Acoustoelastic and Third-Order Elastic Constants for Rail Steel," J. Acoust. Soc. Am., Vol. 60, No. 3, 1976, pp. 741-744.

[8] Santos, A. A. and Bray, D. E., "Ultrasonic Stress Measurement Using PC Based and Commercial Flaw Detectors," Rev. Sci. Instrum., Vol. 71, No. 9, 2000, pp. 3464-3469.

[9] Santos, A. A. and Bray, D. E., "Application of Longitudinal Critically Refracted Waves to Evaluate Stresses in Railroad Wheels," Topics on Nondestructive Testing, Vol. 5, The American Society for Nondestructive Testing, Columbus, OH, 2000.

[10] Bray, D. E. and Chance, B., Practical Aspects of Ultrasonic Stress Measurement, Vol. 19, C. Darvennes, Ed., ASME NDE, San Antonio, TX, 1999, pp. 75-79.

[11] Javadi, Y. and Ahmadi Najafabadi, M., "Comparison Between Contact and Immersion Ultrasonic Method to Evaluate Welding Residual Stresses of Dissimilar Joints," Mater. Design, Vol. 47, 2013, pp. 473-482.

[12] Javadi, Y., Pirzaman, H. S., Raeisi, M. H., and Najafabadi, M. A., "Ultrasonic Evaluation of Welding Residual Stresses in Stainless Steel Pressure Vessel," J. Pres. Ves. Technol., Vol. 135, No. 4, 2013, pp. 1-6.

[13] Javadi, Y., Najafabadi, M. A., and Akhlaghi, M., "Comparison Between Contact and Immersion Method in Ultrasonic Stress Measurement of Welded Stainless Steel Plates," J. Test. Eval., Vol. 41, No. 5, 2013, pp. 1-10.

[14] Javadi, Y., Afzali, O., Raeisi, M. H., and Najafabadi, M. A., "Nondestructive Evaluation of Welding Residual Stresses in Dissimilar Welded Pipes," J. Nondestr. Eval., Vol. 32, No. 2, 2013, pp. 177-187.
[15] Javadi, Y., Sadeghi, S., and Najafabadi, M. A., "Taguchi Optimization and Ultrasonic Measurement of Residual Stresses in the Friction Stir Welding," Mater. Design, Vol. 55, 2014, pp. 27-34.

[16] Rossini, N. S., Dassisti, M., Benyounis, K. Y., and Olabi, A. G., "Methods of Measuring Residual Stresses in Components," Mater. Design, Vol. 35, 2012, pp. 572-588.

[17] Javadi, Y., Akhlaghi, M., and Najafabadi, M. A., "Using Finite Element and Ultrasonic Method to Evaluate Welding Longitudinal Residual Stress Through the Thickness in Austenitic Stainless Steel Plates," Mater. Design, Vol. 45, 2013, pp. 628-642.

[18] Javadi, Y., Pirzaman, H. S., Raeisi, M. H., and Najafabadi, M. A., "Ultrasonic Inspection of a Welded Stainless Steel Pipe to Evaluate Residual Stresses Through Thickness," Mater. Design, Vol. 49, 2013, pp. 591-601.

[19] Javadi, Y., "Investigation of Clamping Effect on the Welding Residual Stress and Deformation of Monel Plates by Using the Ultrasonic Stress Measurement and Finite Element Method," J. Pres. Ves. Technol., Vol. 137, No. 1, 2014.

[20] Javadi, Y., Pirzaman, H. S., Raeisi, M. H., and Najafabadi, M. A., "Ultrasonic Stress Evaluation through Thickness of a Stainless Steel Pressure Vessel," Int. J. Pres. Ves. Pip., Vols. 123-124, 2014, pp. 111-120.

[21] ASME BPVC-VIII-2, An International Code 2010: ASME Boiler \& Pressure Vessel Code, Section VIII: Rules for Construction of Pressure Vessels, Division 2: Alternative Rules, ASME, July 1, 2011, www.asme.org

[22] ASTM E837-13a, Standard Test Method for Determining Residual Stresses by the Hole-Drilling Strain-Gage Method, ASTM International, West Conshohocken, PA, 2013, www.astm.org

[23] Sadeghi, S., Najafabadi, M. A., Javadi, Y., and Mohammadisefat, M., "Using Ultrasonic Waves and Finite Element Method to Evaluate Through-Thickness Residual Stresses Distribution in the Friction Stir Welding of Aluminum Plates," Mater. Design, Vol. 52, 2013, pp. 870-880.

[24] Kapranos, P. A. and Whittaker, V. N., "Difficulties in the Ultrasonic Inspection of 316 Austenitic Stainless Steel Welds Arising from Acoustic Impedance Mismatch," Nondestr. Test. Eval., Vol. 1, No. 3, 1983, pp. 81-92. 